\title{
NUEVAS DIMÁMICAS LITERARIAS, NUEVOS RETOS TEÓRICOS. LA TEORÍA DE LA LITERATURA Y LA MINIFICCIÓN
}

Darío HERNÁNDEZ

Universidad de La Laguna

\begin{abstract}
¡Cuentos largos! ¡Tan largos! ¡De una pájina! ¡Ay, el día en que los hombres sepamos todos agrandar una chispa hasta el sol, que un hombre les dé concentrado en una chispa, el día en que nos demos cuenta que nada tiene tamaño y que, por lo tanto, basta lo suficiente; el día en que comprendamos que nada vale por sus dimensiones - y así acaba el ridículo que vio Micromegas y que yo veo cada día-; y que un libro puede reducirse a la mano de una hormiga porque puede amplificarlo la idea y hacerlo el universo!
\end{abstract}

Juan Ramón Jiménez

U na de las funciones de la Teoría de la Literatura ha sido siempre la reflexión en torno a las clasificaciones genéricas y, por consiguiente, la diferenciación entre unos géneros y otros y el establecimiento de los orígenes y trayectoria de los mismos. En términos generales, no obstante, podemos afirmar que a partir de finales del siglo XIX contábamos, a nivel teórico, con un paradigma genérico estable y que se mantuvo prácticamente inamovible hasta las últimas décadas del siglo XX, al menos en lo que se refiere al ámbito de la narrativa. En los años ochenta, sin embargo, este estático panorama teórico y crítico tocante a la narrativa comenzó a dinamizarse con la introducción en el contexto académico del concepto de microrrelato, gracias a la investigadora de origen cubano Dolores $M$. Koch, quien recordaba en uno de sus artículos aquella pionera experiencia:

Pensé que para presentar un estudio sistemático de estas prosas breves como un subgénero o modalidad nueva, éstas necesitaban un nombre. Como dice el proverbio vasco, «Izena duenak, izana du»: «Lo que tiene nombre existe»; escogí «microrrelato» a falta de uno mejor. No estaba en el diccionario, y esto se me criticó, pero era fácil de entender. [...] y recuerdo cierta insistencia en llamarles fragmentos; pero no me parecían fragmentos de nada, pues se valen por sí mismos, como los sonetos (Koch, 2004: 46$47)^{1}$.

Así pues, el paradigma tradicional de los géneros narrativos basado en una división tripartita (novela, novela corta y cuento) comenzaba por aquel entonces a ir abriendo hueco para la incorporación de una nueva modalidad literaria: el microrrelato, pero no sin notables resistencias

\footnotetext{
${ }^{1}$ Hacía referencia la autora a su ponencia «El micro-relato en México: Torri, Arreola, Monterroso», presentada en el Xx ${ }^{\circ}$ Congreso del Instituto Internacional de Literatura Iberoamericana en 1981.
} 
ejercidas por parte de muchos teóricos y críticos que, como señalaba Koch, cuestionaban su autonomía y entidad genéricas.

Una década más tarde, en los años noventa, comenzaron los investigadores interesados en el asunto a percatarse de que la aparición del hoy considerado «cuarto género narrativo» (AndresSuárez, 2012) había surgido dentro de una corriente estético-literaria de mayor envergadura de lo que se pudo pensar inicialmente y a través de la cual aspectos como la brevedad textual y la concisión estructural se habían convertido en elementos esenciales, determinantes desde el punto de vista creativo. De este modo, el microrrelato no sería ni más ni menos que uno de los resultados — quizá el más próspero e innovador - de una tendencia literaria de corte miniaturista y que se ha venido a denominar y a categorizar en el mundo hispánico como minificción ${ }^{2}$. En este sentido, el término microrrelato «alude a un tipo de texto breve sujeto a un esquema narrativo. La minificción, en cambio, es una supracategoría literaria poligenérica (un hiperónimo), que agrupa a los microtextos literarios ficcionales en prosa, tanto a los narrativos [...] como a los no narrativos» (Andres-Suárez, 2008: 20-21), e incluso, podríamos añadir nosotros, algunos microtextos literarios en verso caracterizados por la síntesis expresiva, como por ejemplo el haiku.

Las numerosas investigaciones sobre este terreno han permitido situar los orígenes históricos de la llamada minificción literaria y, por ende, del microrrelato, entre los inicios del Modernismo y el final de las Vanguardias, periodo en el que se produjo el surgimiento de «la estética de la brevedad del Arte Nuevo», como muy bien ha descrito en varios de sus estudios Domingo Ródenas de Moya (2008: 102-103):

La preferencia por los textos cortos no afectó sólo a la narrativa, sino a todas las expresiones prosísticas, y se extendió a la totalidad de los géneros literarios, desde la lírica al teatro o a la prosa de ideas, y reavivó el interés por formas antiguas como el aforismo, la semblanza o el cuadro dramático, por lo que puede hablarse con propiedad de una «estética de la brevedad».

De esta forma, además de la génesis del microrrelato, en el campo de la narrativa se dieron también otros acontecimientos como, por ejemplo, la fragmentación del discurso novelístico, uno de los rasgos más recurrentes en la novela de vanguardia (Ródenas de Moya, 1998). En la lírica cabe destacar, en este sentido, hechos como la hispanización de un género de origen japonés como es el haiku, que ya antes mencionamos, la difusión del poema en prosa breve o «la preferencia por las estrofas cortas de origen popular (como las seguidillas o soleás) o cultas (como las décimas)» (Gómez Trueba, 2009: 103). En relación con la creación de minificciones teatrales, podríamos mencionar aquí ejemplos como «Diálogo de una violeta malva y una violeta blanca», «Diálogo de las

\footnotetext{
${ }^{2}$ Coincidimos con Lauro Zavala (2005: 16) en que «si se ha llegado a afirmar que la lengua franca de la novela (en su versión canónica del realismo decimonónico) durante la segunda mitad del siglo XIX fue el francés, y que la lengua franca del cuento (en su expresión canónica más tradicional) durante la primera mitad del siglo XX fue el inglés, tal vez la lengua franca de la minificción (como género proteico, ajeno a la tradición del minicuento) ha sido el español, especialmente el escrito en Hispanoamérica, durante la segunda mitad del siglo XX».
} 
alondras» y «Diálogo entre el almendro en flor y la mariposa», de Juan Ramón Jiménez ${ }^{3}$, o los Diálogos de Federico García Lorca ${ }^{4}$, bien estudiados por Irene Andres-Suárez (2010: 134-157). En lo que afecta, por otra parte, a lo que Ródenas de Moya denominaba en la cita anterior «prosa de ideas», tendríamos que hablar del resurgir en la época de los denominados géneros gnómicos, como las máximas, los apotegmas o los aforismos, que a menudo se entremezclaron con lo puramente literario y, a veces, además, con lo humorístico; piénsese, sin ir más lejos, en el caso de las famosas «greguerías» de Ramón Gómez de la Serna, pero también en sus «gollerías», asociadas más bien a lo que se ha definido en ocasiones como microensayo (Andres-Suárez, 2010: 157-173). Por último, ciertamente esta fascinación por la brevedad trajo consigo la reactualización y revitalización de géneros antiguos o en desuso, entre los que destacaron la parábola, la fábula y el bestiario. Estos géneros, sin embargo, no se recuperaron en su mayoría tal cual habían existido en épocas históricas anteriores, sino a través de sus reformulaciones micronarrativas, es decir, que las parábolas, las fábulas y los bestiarios se rescataron pero reconvirtiéndose ahora en microrrelatos parabólicos, fabulísticos y faunísticos respectivamente; léanse, si no, textos como «La resurrección de la rosa» (1892) y «El nacimiento de la col» (1893), ambos de Rubén Darío y que podemos definir como microrrelatos parabólicos (Hernández, 2013a), o el Bestiario de José Moreno Villa (incluido en Evoluciones, 1918), de donde podrá extraer el lector varios microrrelatos sobre animales, unos más próximos a la esencia descriptiva del bestiario y otros más cercanos a la naturaleza narrativa de las fábulas (Hernández, 2013b: 240-241).

Tras el final de las Vanguardias, límite que podemos ubicar cronológicamente en torno al año 1939, con la caída de la Segunda República Española y el comienzo de la Segunda Guerra Mundial, el cultivo de la minificción, en general, y del microrrelato, en particular, continuó hasta la actualidad, reforzado quizá, como algunos investigadores han apuntado, gracias al desarrollo en paralelo de movimientos estéticos como el concretismo poético en los años cincuenta (posterior al concretismo pictórico de los años treinta) o el minimal art a partir de los años sesenta. En cualquier caso, lo cierto es que, visto desde una perspectiva incluso más amplia, este gusto por lo breve, lo conciso o lo esencial (García de Mesa, 2010) se ha manifestado a lo largo de la historia del arte en diferentes momentos, por lo que, si siguiésemos esta línea de pensamiento, corrientes estéticas como el concretismo, el minimalismo o la minificción podrían conectarse, a su vez, con planteamientos tan diversos que irían desde el purismo poético iniciado en Francia a finales del siglo XIX hasta el funcionalismo arquitectónico de Mies van der Rohe y su famoso lema «menos es más», si es que no ahondásemos aún más las raíces hasta el conceptismo ideológico propio del siglo XVII, representado por la sabia sentencia de Baltasar Gracián «lo bueno, si breve, dos veces bueno; y aun lo malo, si

\footnotetext{
${ }^{3}$ «Textos con apariencia de breves cuadros dramáticos que cuentan con una acotación explicativa del escenario donde se sucede la conversación entre los personajes [...], que nos hacen pensar en algunos microtextos dramáticos del español Javier Tomeo o del argentino Marco Denevi» (Gómez Trueba, 2008a: 286).

4 «El paseo de Buster Keaton», «La doncella, el marinero y el estudiante», «Quimera», «Diálogo mudo de los cartujos», «Diálogo de los caracoles», «Escenas del teniente coronel de la Guardia Civil», «Diálogo del Amargo», «Diálogo con Luis Buñuel», «La sabiduría» o «El loco y la loca», «Diálogo de Fabricio y la señora», «Diálogo del dios Pan» y «Diálogo de la Residencia».
} 
poco, no tan malo. Más obran quintas esencias que fárragos»; porque, en última instancia, lo que ha habido en todos estos casos y lo que une, por tanto, todas estas posiciones estético-ideológicas ha sido lo que Lagmanovich (2005: 13-14) describió como «una triple reacción [en todas las artes]: contra la ornamentación por sí misma (es decir, no basada en necesidades funcionales), contra la excesiva extensión y contra la redundancia».

Llegados a este punto, una especial atención merece Edgar Allan Poe, considerado por muchos como el precursor de la teoría minificcional, gracias a su recensión de 1842 de la colección de cuentos Twice-Told Tales, de Nathaniel Hawthorne, en la que no sólo reseñaba la obra de su coetáneo, sino que llevaba a cabo una penetrante reflexión sobre los límites de extensión ideales de poemas y relatos. Ciertamente, su búsqueda de la justa medida textual lo condujo a establecer una serie de criterios estéticos, como el de la «unidad de impresión», ligada a la «totalidad de efecto», que han servido con el tiempo para interpretar mejor la producción de géneros como el poema en prosa o el microrrelato. En su trabajo, Poe (1956: 319) afirmaba cosas como la siguiente:

Durante largo tiempo ha habido un infundado y fatal prejuicio literario que nuestra época tendrá a su cargo aniquilar: la idea de que el mero volumen de una obra debe pesar considerablemente en nuestra estimación de sus méritos. [...] Admitiendo que tan sostenido esfuerzo haya creado una epopeya, admiremos el esfuerzo (si es cosa de admirar), pero no la epopeya a cuenta de aquél. En tiempos venideros el buen sentido insistirá probablemente en medir una obra de arte por la finalidad que llena, por la impresión que provoca, antes que por el tiempo que le llevó llenar la finalidad o por la extensión del «sostenido esfuerzo» necesario para producir la impresión. La verdad es que la perseverancia es una cosa y el genio otra muy distinta; y todo el trascendentalismo pagano no podrá confundirlos.

Un paso importantísimo en el desarrollo de la teoría minificcional, como marco de diverso tipo de investigaciones sobre los géneros breves, ha sido la creación del Congreso Internacional de Minificción, cuyos orígenes se remontan al año 1998 con la organización del I Coloquio Internacional de Minificción, convocado por la Universidad Autónoma Metropolitana de México y coordinado por Lauro Zavala. La mayor parte de los trabajos allí expuestos fueron luego publicados en la revista digital mexicana El Cuento en Red. Revista electrónica de teoría de la ficción breve, en sus números primero y segundo, ambos del año 2000. A este Coloquio siguieron, con periodicidad bianual, los Congresos Internacionales de Minificción, hasta ahora celebrados en Salamanca (2002), Valparaíso (2004), Neuchâtel (2006), Neuquén (2008), Bogotá (2010), Berlín (2012) y Kentucky (2014), y coordinados respectivamente por Francisca Noguerol, Juan Armando Epple, Irene AndresSuárez y Antonio Rivas, Laura Pollastri, Henry González Martínez y Ana Rueda 5 . Otros encuentros académicos relevantes en esta línea han sido, entre otros, las Jornadas Literarias «Menudos universos: el microrrelato en la literatura española contemporánea», celebradas en la Universidad de Valladolid en 2006 y coordinadas por Teresa Gómez Trueba, las Jornadas de Literatura y Crítica: «Minificción Literaria», celebradas en la Universidad de Las Palmas de Gran Canaria en 2008 y coordinadas por Osvaldo Rodríguez Pérez, el XIX Congreso de Literatura Española Contemporánea: «Narrativas de la posmodernidad. Del cuento al microrrelato», celebrado en la Universidad de

\footnotetext{
${ }^{5}$ La novena edición del Congreso Internacional de Minificción tuvo lugar nuevamente en la Universidad Nacional de Neuquén en julio de 2016 y estuvo coordinada por Laura Pollastri.
} 
Málaga también en 2008 y coordinado por Salvador Montesa, o el I Simposio Canario de Minificción: «La minificción y sus límites», celebrado en la Universidad de La Laguna (Tenerife) en 2015 y que tuve el placer de coordinar junto con el profesor José Antonio Ramos Arteaga.

Una de las cosas que ha puesto en evidencia esta importante cantidad de congresos, coloquios, seminarios, jornadas, simposios, etcétera, ha sido las muchas aplicaciones que en diversos frentes tiene la minificción, las cuales deberían potenciarse, guiadas siempre por profundas reflexiones teóricas al respecto que vengan reforzadas, además, por análisis objetivos de los resultados obtenidos, cuestiones de las que la Teoría Literaria, entre otras disciplinas, debería encargarse.

En primer lugar, debemos dedicarle un espacio a las posibilidades que abre la minificción como herramienta en la enseñanza de las lenguas maternas y extranjeras. Géneros minificcionales como el microrrelato han demostrado su eficacia al emplearlos como recursos didácticos, por lo menos así parecen atestiguarlo no ya nuestra propia experiencia docente, sino diversos trabajos como los de Graciela Tomassini y Stella Maris Colombo (1998), Lauro Zavala (1999), Asunción Barreras Gómez (2003), Henry González (2004), María Elena Lorenzín (2004), Christine Muñoz (2010) o Dara García (2015). Una vez se llega a la conclusión lógica de que para aprender un idioma, sea el propio u otro ajeno, hay que leer mucho, los microrrelatos reaparecen ante nosotros como textos con una nueva función de carácter pedagógico. Y es que algunas de sus características básicas, como son la narratividad, la concisión y la ficcionalidad, favorecen su empleo en las situaciones de aprendizaje puestas en marcha en las aulas de idiomas. La narrativa, frente a la lírica, permite a los alumnos un acceso más fácil y directo a los textos, lo cual, sumado a la concisión de los microrrelatos, fomenta aspectos estratégicos como, por ejemplo, la lectura de un mismo texto varias veces, pudiendo así escudriñar al máximo sus particularidades, o la lectura de muchos textos de uno o varios autores pero sobre un mismo tema, ampliando así, además, los valores del multiperspectivismo. La ficcionalidad, por su parte, no cabe duda que incide en la ampliación de la sensibilidad estética de los alumnos y en el aumento de su creatividad, dos de los elementos transversales más importantes en toda clase de lengua.

No podemos tampoco dejar de mencionar los cambios que las teorías literarias minificcionales han supuesto para otra disciplina filológica como es la Historia de la Literatura. La revisión de los paradigmas genéricos realizada a la luz de las más recientes investigaciones minificcionales ha obligado a modificar parte de las definiciones y descripciones de la obra de muchos autores que hasta ahora se habían hecho. Podemos recurrir, por poner un ejemplo, al caso de Federico García Lorca. Hasta el desarrollo de estas teorías e investigaciones de nuevo cuño, varias de las composiciones del genio granadino habían sido clasificadas y publicadas como otra cosa que no eran. Textos escritos en los años veinte como «Telégrafo», «Árbol de sopresas»o «Juego de damas» fueron editados póstumamente como poemas prosa o, simplemente, bajo el membrete de «prosas»; sin embargo, a día de hoy ya podemos definirlos como lo que verdaderamente son, esto es, como microrrelatos, y así aparecen en diversas antologías de micronarrativa. Un primer paso en este sentido lo dio Encarna Alonso Valero con Pez, astro y gafas. Prosa narrativa breve, donde se animaba a leer a Lorca como 
nunca antes había sido leído: como microrrelatista. De manera similar ha ido ocurriendo con todos los precursores del microrrelato español: Juan Ramón Jiménez, Ramón Gómez de la Serna, José Moreno Villa, Luis Buñuel, etcétera. La consolidación de conceptos como el de minificción o el de microrrelato, propios de los siglos XX y XXI,

\footnotetext{
no ha tardado en hacer emerger, o incluso crear — tal y como ha explicado Teresa Gómez Trueba (2008b: 13)-, sus antecedentes. Lo interesante es que hay ciertos elementos de esos supuestos antecedentes que jamás nos hubieran llamado la atención de no haber surgido una obra o tendencia literaria en el futuro que los terminara convirtiendo en precursores de algo.
}

De alguna manera, esto explica también que en países donde nunca antes los historiadores literarios se habían preocupado por la minificción ni por la micronarrativa, hace algunos años estos se hayan puesto ya a indagar al respecto, buscando autores y obras que habían pasado desapercibidos o se habían analizado sin los recursos teóricos apropiados. Este hecho ha conducido y seguirá conduciendo, a su vez, al incremento de las traducciones de libros de minificción, fomentando la labor de los traductores, que siempre va más allá del mero trasvase de los textos de unas lenguas a otras, dadas las implicaciones culturales que conlleva, como sabemos, el conocimiento por parte de un país de la producción literaria de otro. En esta dirección, podrían servir de ejemplo antologías bilingües de microrrelatos publicadas en el año 2016 como, por ejemplo, La vie en bref / La vida en breve (Tucumán, La aguja de Buffon Ediciones), con microrrelatos de autores hispanoamericanos contemporáneos traducidos al francés por profesorado del Departamento de Filología Francesa de la Facultad de Filosofía y Letras de la Universidad Nacional de Tucumán, o Quintaesencias narrativas. Antología del microrrelato español / Chintesente narative. Antologie de micropovestiri spaniole (Iaşi, Editura Universitătii Alexandru Ioan Cuza), cuyos microrrelatos fueron seleccionados y editados por mí y traducidos por Dana Diaconu, Catedrática de Literatura Española de la Universidad Alexandru Ioan Cuza de Rumanía. El objetivo principal de esta última antología fue el de dar a conocer entre los lectores rumanos la micronarrativa española, desde sus orígenes hasta hasta la actualidad y a través de algunos de sus más importantes autores: Juan Ramón Jiménez, José Moreno Villa, Ramón Gómez de la Serna, José Bergamín, Federico García Lorca, Luis Buñuel, Max Aub, Francisco Ayala, Álvaro Cunqueiro, Ana María Matute, Ignacio Aldecoa, Antonio Fernández Molina, José Jiménez Lozano, Fernando Arrabal, Javier Tomeo, Rafael Pérez Estrada, Juan Pedro Aparicio, José María Merino, Luis Mateo Díez, Juan José Millás, Gustavo Martín Garzo y Julia Otxoa. Pero, además, otro de sus propósitos fundamentales fue que sirviese para despertar en los historiadores, teóricos y críticos literarios rumanos el interés en el género del microrrelato, y no ya en el hispánico, sino en el producido en lengua rumana, pues seguro que en la literatura de Rumanía existe un destacable material micronarrativo que está aún por ser analizado y difundido.

En conclusión, ante el surgimiento del fenómeno de la minificción, la Teoría de la Literatura puede transitar por dos caminos bien dispares: el de la resistencia y oposición a los nuevos términos, conceptos y paradigmas genéricos, en beneficio de planteamientos antiguos que no parecen del todo 
ajustarse a unas nuevas realidades estético-literarias, o, por el contrario, el de la aceptación y estudio en su justo contexto, que es el de la creación minificcional, de las innovadoras fórmulas de producción literaria y artística caracterizadas por la brevedad o los pequeños formatos, por la condensación expresiva y la concisión estructural. Géneros literarios como la novela, la novela corta o el cuento, dentro de los narrativos, u otros como el romance o el soneto, dentro de los poéticos, parecen fáciles de tratar temática y formalmente siguiendo los modelos de análisis tradicionales; pero ¿cómo examinar un microrrelato o las reescrituras modernas y en lengua española de un género tan intrínsecamente japonés como es el haiku si no disponemos de renovados y sólidos criterios teóricos distintos de aquellos tradicionales? Y, si hablamos del arte teatral, tampoco nos costará definir las características, las funciones y el lenguaje de una tragedia clásica, un drama romántico o una comedia costumbrista si aplicamos para ello el discurso convencional; pero ¿con qué perspectiva metodológica, si no es una de corte minificcional, analizar, por ejemplo, el «microteatro psicopático» de Javier Tomeo o las nuevas fórmulas del llamado «microteatro por dinero», de auge en ciudades como Madrid? A ello se suma, asimismo, que de un tiempo a esta parte ya no sólo se habla de minificción literaria, sino que géneros como el nanometraje, el cineminuto, el spot publicitario o, incluso, el videoclip, se han agrupado bajo los conceptos de minificción cinematográfica y minificción audiovisual (Zavala: 2008) ${ }^{6}$.

Indudablemente, una nueva realidad literaria y artística se presenta ante los teóricos, y son estos los que deben hacer uso de nuevos recursos, herramientas y métodos hermenéuticos capaces de hacer frente a ella y poder interpretarla y explicarla de la mejor y más adecuada manera posible.

\section{Bibliografía}

Alonso VAlero, Encarna, ed. (2008): Pez, astro y gafas. Prosa narrativa breve. Palencia, Menoscuarto.

ANDRES-SUÁREZ, Irene, (2008): «Prólogo», en Irene ANDRES-SUÁREZ y Antonio RIVAS, eds., La era de la brevedad. El microrrelato hispánico. Palencia, Menoscuarto, pp. 11-21. (2010): El microrrelato español. Una estética de la elipsis. Palencia, Menoscuarto. ed. (2012): Antología del microrrelato español (1906-2011). El cuarto género narrativo. Madrid, Cátedra.

Aullón de Haro, Pedro (2002): El jaiku en España. La delimitación de un componente de la poética de la modernidad. Madrid, Hiperión.

BARRERAS GÓMEZ, Asunción (2003): El estudio literario de la narración breve y su utilización en el contexto docente. La Rioja, Universidad de La Rioja.

GARCÍA Berrio, Antonio, y Huerta CAlvo, Javier (1995): Los géneros literarios. Sistema e historia. Madrid, Cátedra.

\footnotetext{
${ }^{6}$ Muchísimos son los nanofilmes presentados en certámenes cada más importantes, como es el caso del Iberminuto. Festival de Cine Minuto de España, el Festival Metropolitano de Cineminuto y Nanometraje (México) o el Festival Internacional de Cineminutos de Córdoba (Argentina).
} 
GARCÍA DE MESA, Roberto (2010): «Interdiscursividad de lo breve y lo esencial en los modelos de minificción», en Osvaldo RODRÍGUEZ PÉREZ, ed., Los mundos de la minificción. Valencia, Aduana Vieja, pp. 53-70.

GARCÍA PERERA, Dara (2015): La enseñanza de la gramática en E/LE a través del microrrelato: un enfoque holístico. Gran Canaria, tesina inédita.

Gómez TruebA, Teresa (2008a): «Juan Ramón Jiménez y el arte de descontar el cuento», en Irene ANDRES-SUÁREZ y Antonio RIVAS, eds., La era de la brevedad. El microrrelato hispánico. Palencia, Menoscuarto, pp. 275-300.

- (2008b): «Acerca del camino estético que nos condujo al microrrelato: el ejemplo de Juan Ramón Jiménez», Ínsula, 741, pp. 13-17.

- (2009): ““Arte es quitar lo que sobra”. La aportación de Juan Ramón Jiménez a la poética de la brevedad en la literatura española», en Salvador MONTESA, ed., Narrativas de la posmodernidad. Del cuento al microrrelato. Málaga, AEDILE, pp. 91-115.

GonZÁlez, Henry (2004): «La didáctica del minicuento y su desarrollo en ambientes hipermediales», en Francisca Nogutrol, ed., Escritos disconformes. Nuevos modelos de lectura. Salamanca, Universidad de Salamanca, pp. 303-315.

HERnÁndeZ, Darío (2013a): «Más de un siglo de microrrelatos. Rubén Darío como precursor del microrrelato hispánico», en Concepción REverTe Bernal, ed., Diálogos culturales en la Literatura Iberoamericana. Madrid, Verbum, pp. 514-521.

(2013b): El microrrelato en la literatura española. Orígenes históricos: Modernismo y Vanguardia. Tenerife, Universidad de La Laguna.

Koch, Dolores M. (2004): «¿Microrrelato o minicuento? ¿Minificción o hiperbreve?», en Francisca NoGUEROL, ed., Escritos disconformes. Nuevos modelos de lectura. Salamanca, Universidad de Salamanca, pp. 45-51.

LAGMANOVICH, David (2005): «Introducción: El microrrelato en nuestra cultura», en David Lagmanovich, ed., La otra mirada. Antología del microrrelato hispánico. Palencia, Menoscuarto, pp. 7-33.

LORENZín, María Elena (2004): «Fast Fiction en la clase de español avanzado: Una experiencia creativa en las Antípodas», en Francisca Noguerol, ed., Escritos disconformes. Nuevos modelos de lectura. Salamanca, Universidad de Salamanca, pp. 317-333.

MuÑOZ, Christine (2010): «Dinámica del microrrelato», en Osvaldo RoDRíGUEZ PÉREZ, ed., Los mundos de la minificción. Valencia, Aduana Vieja, pp. 179-189.

POE, Edgar Allan (1956): «Hawthorne», en Julio CORTÁZAR, trad., Obras en prosa II: Narración de A. G. Pym; Ensayos y críticas; Eureka. San Juan / Madrid, Universidad de Puerto Rico / Revista de Occidente, pp. 313-327.

RóDEnAS DE MoyA, Domingo (2008): «El microrrelato en la estética de la brevedad del Arte Nuevo», en Irene ANDRES-SUÁREZ y Antonio RIVAS, eds., La era de la brevedad. El microrrelato hispánico. Palencia, Menoscuarto, pp. 77-121. 
204 Tropelías. Revista de Teoría de la Literatura y Literatura Comparada, 27 (2017) Darío Hernández

(1998): Los espejos del novelista: modernismo y autorreferencia en la novela vanguardista española. Barcelona, Península.

TOMASSINI, Graciela, y MARIS COLOMBO, Stella (1998): Comprensión lectora y producción textual. Minificción hispanoamericana. Rosario, Fundación Ross.

ZAVALA, Lauro (2008): «La minificción audiovisual: hacia un nuevo paradigma en los estudios de la minificción», en Irene ANDRES-SUÁREZ y Antonio RIVAS, eds., La era de la brevedad. El microrrelato hispánico. Palencia, Menoscuarto, pp. 207-229.

(2005): La minificción bajo el microscopio. México, Universidad Pedagógica Nacional.

ed. (1999): Lecturas simultáneas. La enseñanza de la lengua y la literatura con especial atención al cuento ultracorto. México, Universidad Autónoma de México. 